\title{
Microwave Treated Gardenia J asminoides Leaves for Adsorptive Removal of Direct Red-28 Dye in Environmental Benign Way
}

\author{
RABIA REHMAN ${ }^{2 *}$, FARAH KANWAL ${ }^{1}$, LIVIU MITU2* \\ IInstitute of Chemistry, University of the Punjab, Lahore-54590, Pakistan \\ ${ }^{2}$ University of Pitesti, Department of Chemistry, 1 Targu din Vale Str. 110040, Pitesti, Romania
}

\begin{abstract}
In this work, microwave treated Gardenia jasminoides leaves (MTGL) were employed to remove Direct Red-28 (DR) dye from aqueous medium. Most of DR dye contents removed within 30 minutes at $\mathrm{pH} 2$ and $350 \mathrm{ppm}$ dye concentration by $0.02 \mathrm{mg}$ MTGL. Maximum dye adsorbed by MTGL ( $88.50 \mathrm{mg} / \mathrm{g})$ was approximately triple than non treated simple Gardenia jasminoides leaves $(34.13 \mathrm{mg} / \mathrm{g})$. Adsorption modelling of equilibrium data indicated that removal of DR dye by MTGL followed Langmuir, Freundlich and pseudosecond order kinetic models, having exothermic nature. Desorption studies indicated the reusability of MTGL on larger scale. So it is clear that Gardenia jasminoide leaves can be used on larger scale for anionic dye removal after treatment with formalin in efficient manner.
\end{abstract}

Keywords: Gardenia jasminoides leaves, Direct Red-28, Adsorption isotherm, Thermodynamics, Kinetics

Most of the diseases of human beings are related to environmental pollution especially with water pollution due to rapid growth and industrialization. Synthetic dyes are main culprits among different waste materials which are contaminating water and environment. They are chemically stable and resistant to biodegradation so they persist in the water bodies for long times. So different methods were used to remove them before their discharge into main water stream, like: Fenton and Fenton like process [1], co-precipitation [2], photo-catalysis [3], gliding arc discharge [4], electrochemical treatment [5], fungal degradation [6], photo-catalysis [7] and adsorption [8, 9], but these methods are mostly expensive and sludge disposal becomes a secondary issue in them. So adsorption is adopted to remove dyes using activated charcoal or other adsorbents from indigenous sources, like: leaves, fruit peels, seeds and other bio-waste materials. These materials are cheap, easy to find and abundant in nature which makes them attractive alternatives to activated carbon [1].

Direct Red-28 (DR) is an azo type acidic dye as indicated from its structure given in (fig. 1). It is usually employed for dyeing leather, cotton, paper, silk, etc. It is also used for staining histological tissues samples and bacterial strains. It is very toxic for phytoplankton and human beings [10], because harmful substances, like: carbon and nitrogen oxides produced by its decomposition, which are very obnoxious for environment. Various adsorbents were tried by different researchers for its removal from aqueous medium on batch scale, like: rice husk, wheat husk, chitosan, pine leaves, Myrtuscommunis, roots of Eichhornia Crassipes, pomegranate, Phoenix dactylifera seeds, J ujuba seeds, sugarcane bagasse and other agricultural wastebased materials [11-26]. But still there is need to explore

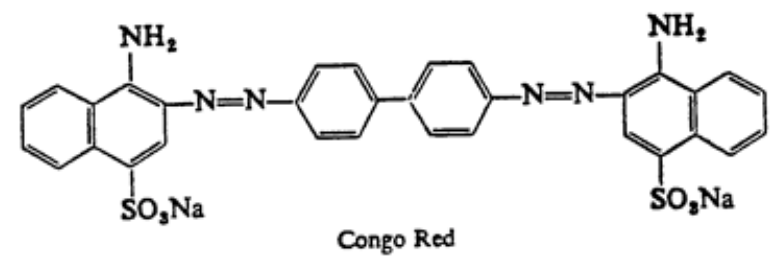

Fig. 1. Structural formula of Direct Red-28 dye more materials from local resources of native areas with high adsorption capacity and selectivity for anionic dyes that will improve the efficiency and cost effectiveness of this process.

In this project, Gardenia jasminoides leaves are used for removal of DR dye after microwave treatment. It is an evergreen shrub type plant locally known as Jasmin. It is found usually in homes, offices and jogging tracks due to its fragrance, beauty of glossy foliage and splendid flowers. Its leaves and flowers are used in Ayurvedic medication. Its fruit is used as a yellow dye for coloring clothes and food stuff [27, 28]. In this work, Gardenia jasminoides leaf powder was treated with microwaves, by keeping them in silicon carbide crucible assembly. Because of using silicon carbide assembly in microwave oven, it converts into charcoal within few minutes, which saves time and energy, ultimately reduces cost of this project [29]. Adsorption process parameters were optimized using this modified adsorbent for performing isothermal, kinetic and thermodynamic modelling of equilibrium data. After that desorption studies were carried outfor checking reusability and regeneration of adsorbent.

\section{Experimental part}

\section{Chemicals and Instruments}

Direct Red-28 dye (Merck), $\mathrm{HCl}$ (Merck), $\mathrm{NaOH}$ (Merck), grinder (Philips), Microwave oven (Dawlance), pH meter, UVD-3500 spectrometer (Labomed) and FT-IR (Perkin Elmer-ATR) were employed here.

\section{AdsorbentPreparation}

Gardenia jasminoides leaves were collected from the surroundings ofhome institute, washed, dried, ground to fine powder and kept in plastic jars, labelled as SGL (simple Gardenia jasminoides leaves).

\section{Microwave treatment of adsorbent}

SGL sample was placed in Silicon carbide crucible assembly and put in microwave oven for 5-6 min. The carbonized material, thus obtained, was cooled to room temperature and stored in air tight jar with label MTGL (Microwave treated Gardenia jasminoides leaves). This

*email: grinorganic@yahoo.com; ktm7ro@yahoo.com; Phone: 0040/725160304 


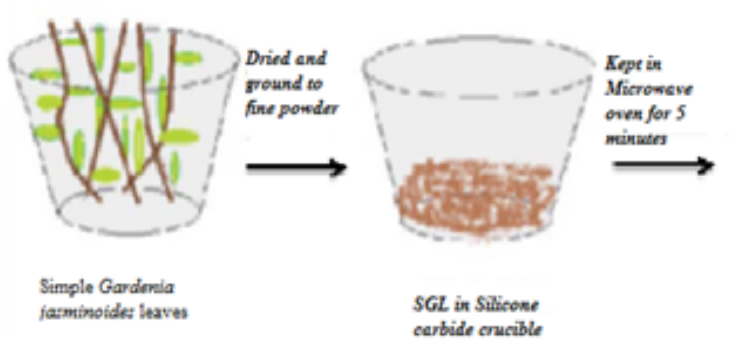

process is diagrammatically represented in (fig. 2). Both SGL and MTGL were characterized by FT-IR and SEM.

\section{Synthetic waste water preparation}

For optimization of operational parameters for removal of Direct Red-28 from waste water, its stock solution of $1000 \mathrm{ppm}$ was prepared using $0.1 \mathrm{~g}$ of dye in $100 \mathrm{~mL}$ of deionized water. Further standards and working solutions were prepared from it by required dilutions.

\section{Adsorption parameters optimization experiments}

Various factors effecting removal of Direct Red-28 from waste water by adsorption were optimized one by one in batch mode using $25 \mathrm{ppm}$ dye solution in STP conditions. These includes: pH, amount of MTGL adsorbent, shaking speed, time of contact and temperature as explained earlier in previous literature [30-32].

Mechanistic study by isothermal modelling of equilibrium data

For this purpose, optimized conditions of all parameters were applied on higher concentration of dye solutions simultaneously and resulting equilibrium data was analysed by isothermal models by equations (1) and (2).

Langmuir isotherm:

Freundlich isotherm:

$$
\mathbf{C}_{\mathrm{e}} / \mathbf{q}=\mathbf{C}_{\mathrm{e}} /\left(\mathbf{q}_{\mathbf{m}} \mathbf{b}\right)+\mathbf{C}_{\mathrm{e}} / \mathbf{q}_{\mathbf{m}}
$$

$$
\log q_{e}=\log K_{F}+\frac{1}{n} \log C_{e}
$$

where $C_{e}$ is final Direct Red-28 concentration (ppm), $q_{m}$ is maximum dye removal capacity of MTGL in $\mathrm{mg} / \mathrm{g}, b, n$ and ' $\mathrm{K}_{\mathrm{F}}$ ' are Langmuir, Freundlich and physiosorption constants.

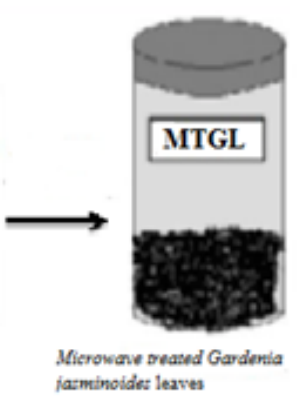

Fig. 2. Schematic representation of preparation of adsorbent

Desorption of dye

For regenerating MTGL after removal of Direct Red-28 from synthetic waste water, desorption was carried out in batch mode using $250 \mathrm{ppm}$ dye solution and $0.2 \mathrm{~g} \mathrm{MTGL}$. The dye loaded MTGL was shaken at $100 \mathrm{rpm}$ for $2 \mathrm{~h}$ with $25 \mathrm{~mL}$ of three eluents: $0.01 \mathrm{M} \mathrm{NaOH}, 0.01 \mathrm{M} \mathrm{HCl}$ and deionized water. Then after filtration dye concentration was estimated in filtrate to calculate \% age desorption of dye by equation (3):

$$
\text { Desorption...(\%) }=\frac{C_{\text {des }}}{C_{\text {ad }}} \times 100
$$

where $C_{d e s}$ and $C_{a d}$ are the remaining and initial concentration of Direct Red-28 (ppm) [33].

\section{Results and discussions}

Adsorbent characterization

FT-IR spectra of simple (SGL) and microwave treated leaves of Gardenia jasminoides (MTGL) was compared in (fig. 3). A broad band nearby $3200 \mathrm{~cm}^{-1}$ indicated $\mathrm{O}-\mathrm{H}$ group.

$\mathrm{N}-\mathrm{H}$ and $\mathrm{O}-\mathrm{H}$ stretching vibrations were represented by peaks in $3500-2800 \mathrm{~cm}^{-1}$ range. Unsaturation due to $C \equiv C$ and $\mathrm{C} \equiv \mathrm{N}$ was indicated by peaks near $2300 \mathrm{~cm}^{-1}$ and $2100 \mathrm{~cm}^{-1}$. The peaks in 1760-1670 $\mathrm{cm}^{-1}$ range were due to carbonyl group stretching frequencies. The peaks near $1430 \mathrm{~cm}^{-1}$ and $1050 \mathrm{~cm}^{-1}$ were attributed to $\mathrm{C}-\mathrm{H}$ and $\mathrm{C}-\mathrm{O}$ $\mathrm{C}$ stretching vibrations. For acid and base treated leaf samples, small shifts in peak values was found in case of hydroxyl, amine and carbonyl groups which indicated the presence of different functional groups possibly liable for Direct Red-28 adsorption on Gardenia jasminoides leaves [34].

Physico-chemical characterization of microwave treated Gardenia jasminoides leaves (MTGL) was given in table 1. Dye solution having $\mathrm{pH}$ less than $\mathrm{pH}$ pzc of adsorbent would result in positive charged on adsorbent surface, resulting in a decreased adsorption capacity.

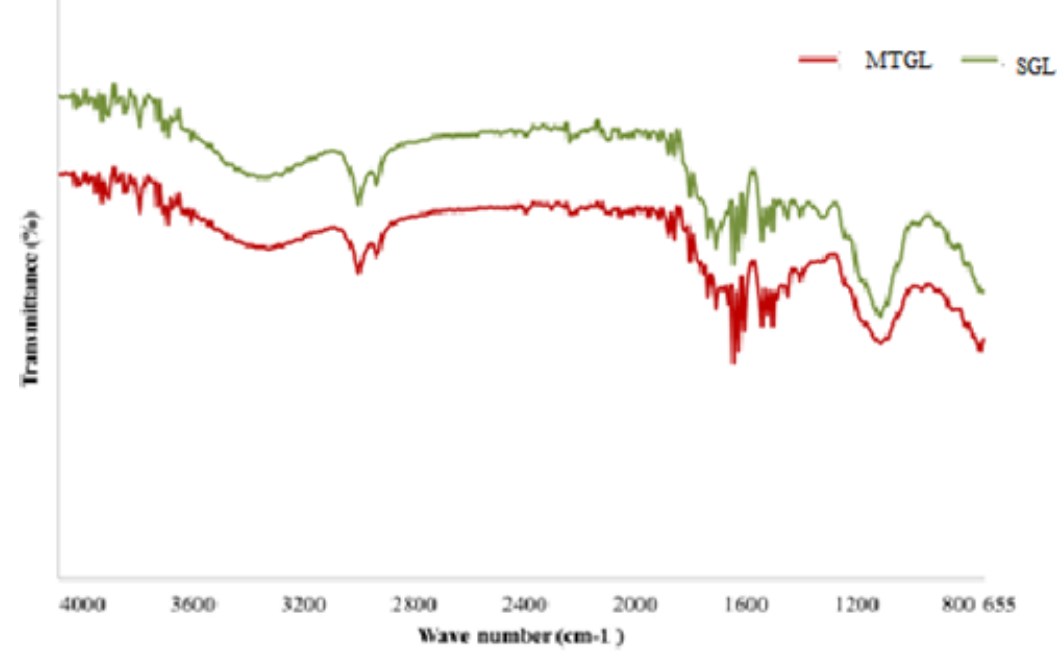

Fig. 3. FT-IR spectrum of simple (SGL) and microwave treated Gardenia jasminoides leaves (MTGL) 


\begin{tabular}{|l|c|c|}
\hline \multirow{2}{*}{ Characteristics } & \multicolumn{2}{|c|}{ Values } \\
\cline { 2 - 3 } & SGL & MTGL \\
\hline Ash content $(\%)$ & 87.6 & 92.2 \\
\hline Moisture $(\%)$ & 8.47 & 1.17 \\
\hline Bulk density $\left(\mathrm{g} / \mathrm{cm}^{3}\right)$ & 0.196 & 0.112 \\
\hline \multirow{3}{*}{ Acid groups $(\mathrm{mmol} / \mathrm{g})$} & Total $=9.91$ & Total $=4.31$ \\
\cline { 2 - 3 } & Carboxylic and lactonic =5.27 & Carboxylic and lactonic $=2.13$ \\
\cline { 2 - 3 } & Phenol =4.64 & Phenol = 1.67 \\
\hline Basic groups (mmol/g) & 7.2 & 4.3 \\
\hline pHpzc & 6.65 & 6.12 \\
\hline
\end{tabular}

Table 1

PHYSICO-CHEMICAL CHARACTERIZATION OF THE MICROWAVE TREATED GARDENIA JASMINOIDES LEAVES

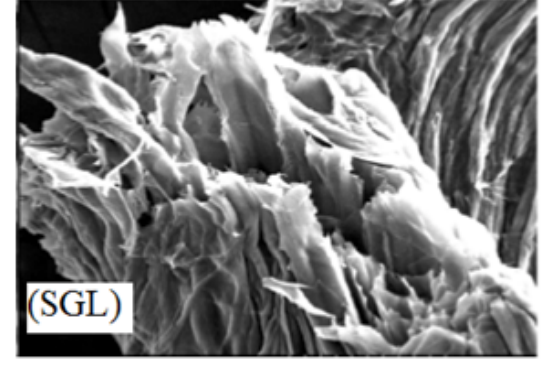

The Gardenia jasminoides leaves has many irregular structures on its surface, as shown in the SEM charts for SGL and MTGL (fig. 4), which gives a high specific surface area with good adsorption capacity. Substantial chemical changes take place on the surface of MTGL, thus changing its structure, which are consistent with physical modification. The surface of SGL is uneven with large gaps and some pore structures, which greatly increase its specific surface area. In MTGL specific surface area increased to $634 \mathrm{~m}^{2} / \mathrm{g}$ as compared to SGL, suggesting that drastic increase in it is a major factor contributing to the great improvement of sorption capacity for DR dye. This suggests that the enhanced sorption capacity is because of chemical factors, which suggests the biosorption process is chemisorption and best simulated by Langmuir isotherm.

\section{Adsorption of Direct Red-28 dye}

a) Effect of an initial concentration

Initial concentration of DR dye was varied 50 to 450 ppm for investigating optimized condition of concentration that can be removed by MTGL and graphically shown in (fig. 5). It is obvious from (fig. 5) that sorption capacity of MTGL enhanced with increase of initial concentration of dye. Usually greater initial concentration of dye is helpful in mass transfer of dye molecules in deeper surface of MTGL because of more interaction with inner layers of sorbent. In beginning all active sites are vacant, so adsorption process is rapid, but with rise in concentration of dye, it starts propelling further dye molecules from adsorption. The maximum removing capacity of MTGL using 350 ppm of DR is $61.24 \mathrm{mg} / \mathrm{g}$.

Comparable phenomenon was observed while bentonite is used for DR removal [10].

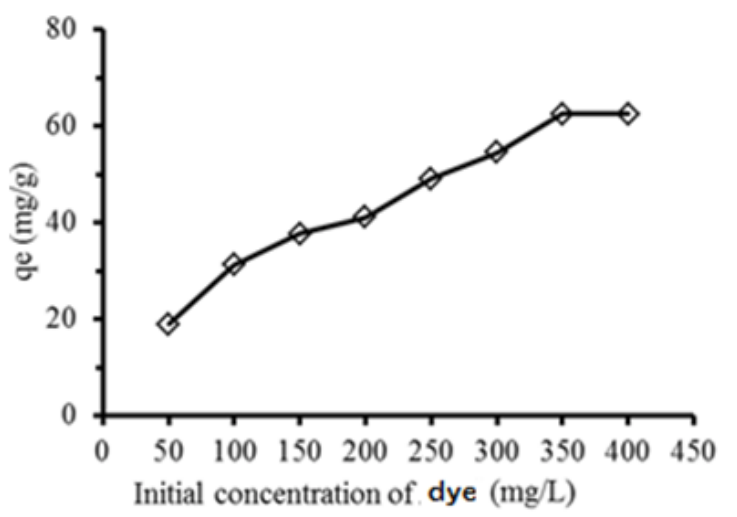

Fig. 5. Initial DR concentration effect on adsorption capacity of MTGL b) Effect of $p \mathrm{H}$

Dye solution $\mathrm{pH}$ effects protonation and deprotonation of MTGL surface, which in turns effects its dye removal capacity. So its optimized conditions were explored using 25 ppm DR solution having $0.2 \mathrm{~g}$ MTGL. Solution $\mathrm{pH}$ was varied from 1.0 to 8.0 and remaining dye concentration was estimated after $30 \mathrm{~min}$ in dye solution. The results were summarized in (fig. 6), which shows that more adsorption occurs in acidic conditions, like: $70.75 \mathrm{mg} / \mathrm{g}$. It is reduced in basic conditions to $24.62 \mathrm{mg} / \mathrm{g}$ at $\mathrm{pH}$ 8.0. The optimum $\mathrm{pH}$ for $\mathrm{DR}$ removal is around 2.0. In acidic conditions, MTGL sorbing capacity of DR dye is higher due to the fact that electro-static interfaces among positive charge carboxylic groups of MTGL surface (MTGL-COOH${ }_{2}^{+}$) and anionic sulfonate groups of DR dye are higher in lower $p \mathrm{H}$ range. As $\mathrm{pH}$ of dye solution increase, deprotonation occurs, leading to deduced adsorption capacity of MTGL. It is explained in following equations (4) and (5). Same behaviour is observed chitosan hydrogel beads [12-14].

$$
\begin{aligned}
& \text { MTGL-COOH }{ }_{2}^{+}+\text {DR-SO } \mathrm{H} \rightarrow \rightarrow \text { MTGL-COOH }{ }_{2}{ }^{+} \mathrm{SO}_{3} \mathrm{H}^{-}-\mathrm{DR}
\end{aligned}
$$

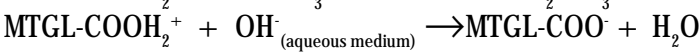

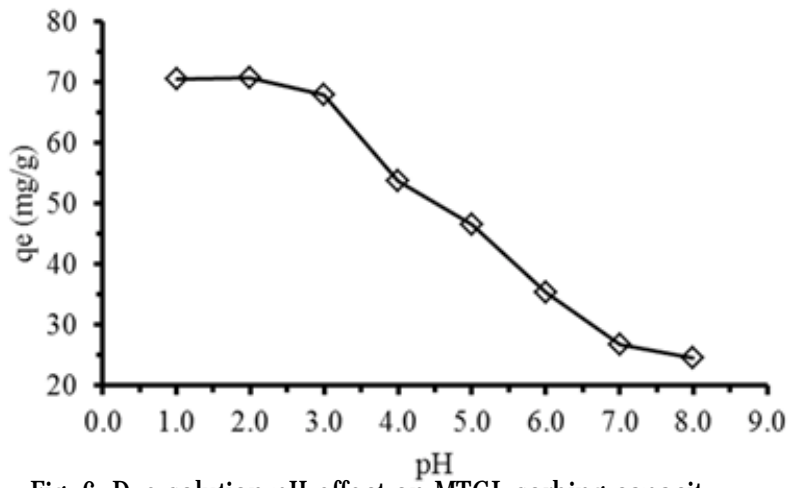

Fig. 6. Dye solution pH effect on MTGL sorbing capacity

c) Effect of MTGL dosage

Amount of MTGL used for sorptive removal of DR dye is an important parameter during isothermal investigation of equilibrium data. So, its optimized conditions was explored by varying MTGL amount from $0.02 \mathrm{~g}$ to $0.2 \mathrm{~g}$ and results were shown in (fig. 7).

It is clear from this figure that dye removal capacity of MTGL decreases with its increasing amount from 0.02$0.04 \mathrm{~g}$. Maximum removal of DR dye occurred at $0.02 \mathrm{~g}$ MTGL dose. It is due to the fact that total exposed active sites area decreses by increasing adsorbent dose due to overlapping and aggregation of adsorption sites and 


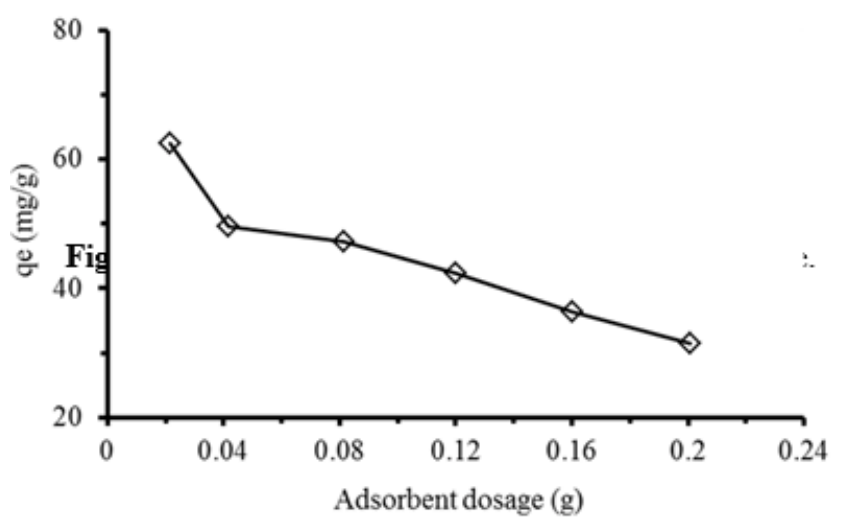

Fig. 7. Effect of MTGL dosage

functional groups. So least amount of more active MTGL is required [29].

d) Effect of contact time

Time of contact between DR dye solution and MTGL affects the kinetics of adsorption process. Initially dye removal is rapid due to the availability of fresh active sites on MTGL, which was decreased later on. It is obvious from (fig. 8)

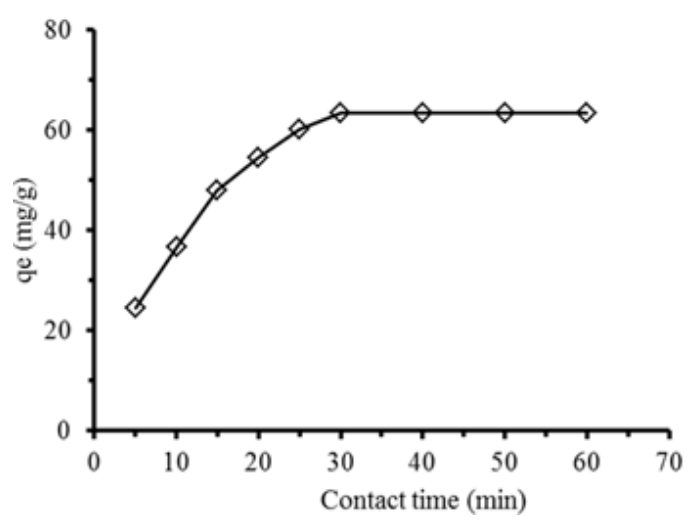

Fig. 8. Contact time effect on the adsorption of DR by MTGL

From (fig. 8), it is depicted that DR sorption capacity of MTGL first rise speedily and then become constant with passage of time, as equilibrium established within $30 \mathrm{~min}$, between sorptive removal of dye and its desorption on MTGL surface. On later stages of sorption, dye removal by MTGL is likely due to attachment of DR molecules on inner available sorption sites in MTGL. This behaviour is observed during pseudo-second order kinetic model, as followed in most of dye removal processes by adsorption on agro-waste materials.

\section{Thermodynamic study of the dye adsorption}

For investigating thermodynamic aspects of MTGL sorption capacity for removal of DR dye, optimized conditions of adsorption were applied simultaneously by varying dye solution temperature. Resulting equilibrium data were cumulated by equations ( 6 - 8 ) in (fig. 9) to calculate Gibbs free energy change $\left(\Delta \mathrm{G}^{\circ}\right)$, entropy change $\left(\Delta \mathrm{S}^{\circ}\right)$ and enthalpy change $\left(\Delta \mathrm{H}^{\circ}\right)$ and results were tabulated in table 2.

$$
\begin{aligned}
& \Delta G^{\circ}=-R T \ln K_{d} \\
& K d=\frac{q_{e}}{C e} \\
& \ln K d=-\frac{\Delta H^{\circ}}{R T}+\frac{\Delta S^{\circ}}{R}
\end{aligned}
$$

where $R$ is the gas constant ( $8.314 \mathrm{~J} / \mathrm{mol} . \mathrm{K}), T$ is absolute temperature in $\mathrm{K}$ and $K_{d}$ is the equilibrium constant. The values of $\Delta \mathrm{S}^{\circ}$ and $\Delta \mathrm{H}^{\circ}$ were determined from slope and the intercept of the Van't Hoff graph of $\ln K_{d}$ and $1 / T$ (fig. 9).

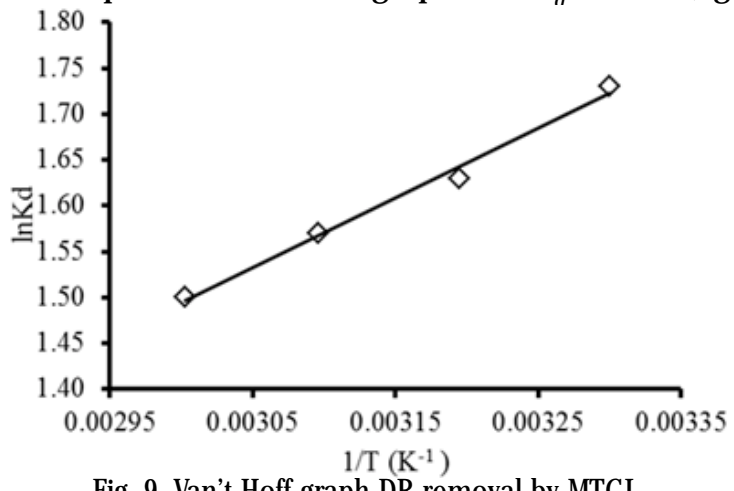

Fig. 9. Van't Hoff graph DR removal by MTGL

On equilibrium, negative $\Delta \mathrm{G}^{\circ}, \Delta \mathrm{S}^{\circ}$ and $\Delta \mathrm{H}^{\circ}$ depicted the spontaneity of sorptive removal of DR by MTGL having exothermic nature and lower disorder values [30-33]. High temperature disfavours sorption process due to accelerating behaviour of dye molecules in solution, which inhibits its sorptive removal by MTGL.

Kinetic modelling of equilibrium data of $D R$ adsorption

This will help in understanding nature of adsorption process. The pseudo second-order model was used for analysing chemisorption of DR by MTGL by following equation (9) [30-32].

$$
\frac{t}{q_{t}}=\frac{1}{k_{2} q_{e}^{2}}+\frac{1}{q_{e}} t
$$

Here $q_{e}$ and $q_{t}$ are DR removal capacity $(\mathrm{mg} / \mathrm{g})$ for pseudo-second-order adsorption of DR adsorbed on MTGL at equilibrium and on time $t(\mathrm{~min})$ respectively and $k$ is the rate constant ( $\mathrm{g} / \mathrm{mg} \cdot \mathrm{min})$. Its value was cumulated from (fig. 10) and tabulated in table 3 for comparison.

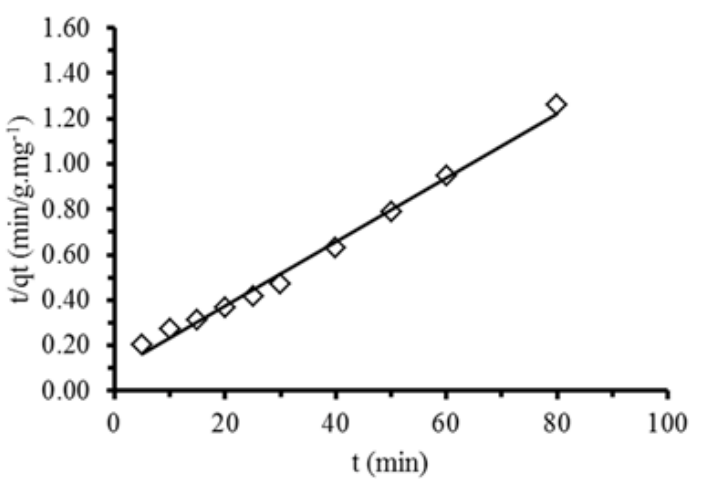

Fig. 10. The pseudo-second-order kinetic data of Direct Red-28 adsorption using MTGL at $303 \mathrm{~K}$

\begin{tabular}{|c|c|c|c|c|c|c|}
\hline \multirow{2}{*}{$\begin{array}{c}\Delta \mathbf{H}^{\circ} \\
(\mathrm{kJ} / \mathrm{mol})\end{array}$} & $\Delta \mathrm{S}^{\circ}(\mathrm{kJ} / \mathrm{mol} . \mathrm{K})$ & \multicolumn{4}{|c|}{$\Delta \mathrm{G}^{\circ}(\mathrm{kJ} / \mathrm{mol})$} & $\mathbf{R}^{2}$ \\
\cline { 3 - 7 } & & $305 \mathrm{~K}$ & $315 \mathrm{~K}$ & $325 \mathrm{~K}$ & $335 \mathrm{~K}$ & \\
\hline-6.25 & -6.31 & -13.62 & -13.87 & -14.27 & -14.31 & 0.981 \\
& & & & & & \\
\hline
\end{tabular}

Table 2 THERMODYNAMIC PARAMETERS OF DIRECT RED-28 ADSORPTION USING MICROWAVE TREATED GARDENIA JASMINOIDES LEAVES 
Table 3

THE KINETIC PARAMETERS OF DIRECT RED-28 ADSORPTION USING MICROWAVE TREATED GARDENIA JASMINOIDES LEAVES (MTGL) AT 303 K

\begin{tabular}{|c|c|c|c|c|}
\hline \multicolumn{2}{|c|}{$q_{\text {o,esp }}(\mathrm{mg} / \mathrm{g})$} & \multicolumn{2}{|c|}{ Pseudo-first order } & \multicolumn{2}{c|}{ Pseudo-second order } \\
\hline \multirow{3}{*}{63.54} & $q_{\mathrm{c}}(\mathrm{mg} / \mathrm{g})$ & 45.51 & $q_{\mathrm{c}}(\mathrm{mg} / \mathrm{g})$ & 62.93 \\
\cline { 2 - 5 } & $k_{J}(\mathrm{~min})$ & 0.11 & $k_{2}(\mathrm{~g} / \mathrm{mg} \cdot \mathrm{min})$ & 0.16 \\
\cline { 2 - 5 } & $\mathrm{R}^{2}$ & 0.8412 & $\mathrm{R}^{2}$ & 0.9919 \\
\hline
\end{tabular}

Table 4

ISOTHERM PARAMETERS CALCULATED FOR THE ADSORPTION OF DR BY MTGL

\begin{tabular}{|c|c|c|c|c|c|c|}
\hline \multirow{2}{*}{ Adsorbent } & \multicolumn{3}{|c|}{ Langmuir Isotherm } & \multicolumn{3}{c|}{ Freundlich Isotherm } \\
\cline { 2 - 7 } & $\mathbf{q}_{\max }(\mathbf{m g} / \mathbf{g})$ & $\mathbf{b}$ & $\mathbf{R}^{2}$ & $\mathbf{K}_{\mathbf{F}}$ & $\mathbf{n}$ & $\mathbf{R}^{2}$ \\
\hline SGL & 35.13 & 0.008 & 0.9861 & 0.99 & 1.67 & 0.9942 \\
\hline MTGL & 84.50 & 0.013 & 0.9918 & 5.50 & 2.22 & 0.9676 \\
\hline
\end{tabular}

Kinetic parameters for DR removal by MTGL were also calculated bypseudo firstorder model and reported in table 3 for comparison purpose. It is obvious from this data that pseudo-firstorder kinetic model is not valid on this scheme due to lower correlation coefficient value i.e. $R^{2}=0.8412$. Also there is huge difference between cumulated adsorption capacity $\left(q_{e}\right)$ and experimental adsorption capacity $\left(q_{e, \text { exp }}\right)$. Whereas these values are in compatible mode, when pseudo-second order model was applied. So removal of DR dye by MTGL follows pseudo-second order model, which is also obvious from effect of time parameters investigation, that indicated that sorption on initial stages is rapid, followed by slower diffusion of DR molecules in inner layers of MTGL.

Mechanistic studies of DR removal by MTGL

Isothermal modelling of equilibrium data was done for this purpose and results were tabulated in table 4. Langmuir model constant ' $b$ ' is further used to calculate separation factor $\left(R_{L}\right)$ by equation (10) [30-34].

$$
\frac{t}{q_{t}}=\frac{1}{k_{2} q_{e}^{2}}+\frac{1}{q_{e}} t
$$

here $K_{L}=b$ and $C_{0}$ is $25 \mathrm{ppm}$ of DR. Its value indicates the nature of adsorption process at equilibrium, i.e: $R_{1}>1.0$ unfavorable; $R=1.0$ linear and $R_{<}<1$.0 favourable process. For DR sorption by MTGL, its value is 0.18 , suggesting favourable biosorption. Maximum removal of dye $q_{\max }$ value is almost 2.5 times greater than from Simple leaves of Gardenia jasminoides (SGL) as compared to microwave treated leaves. Another favourable value is $K_{f}$ which is physiosorptive removal of DR dye by MTGL. It's value is also 5 times greater in microwave treated leaves, which indicated that surface morphology of Gardenia jasminoides leaves were changed extremely after modification. This fact is also supported by SEM images of samples. Overall chemisorption mode is dominant over physiosorption due to larger values of correlation coefficient of Langmuir model in both cases.

\section{Desorption of Direct Red-28}

For regeneration of MTGL using $\mathrm{NaOH}(p \mathrm{H}=8.0-12.0)$, deionized water (DI-water, $p \mathrm{H}=6.6)$ and $\mathrm{HCl}(p \mathrm{H}=1.0$ 5.0) were tested as eluents and desorption capacity were compared in (fig. 11).

It indicated that using $\mathrm{HCl}$, DI-water and $\mathrm{NaOH}$, desorption percentages increases as 19.6-81.4, 82.7 and $90.2-93.7$, respectively. More desorption of DR dye occurred when $\mathrm{NaOH}$ solutions were employed as eluents. It can be attributed to acidic nature of DR dye and protonated nature of MTGL as observed during optimization of $\mathrm{pH}$ conditions. $\mathrm{NaOH}$ helps in deprotonation of MTGL surface, which in turns desorb DR dye and again active sites become available for reuse.

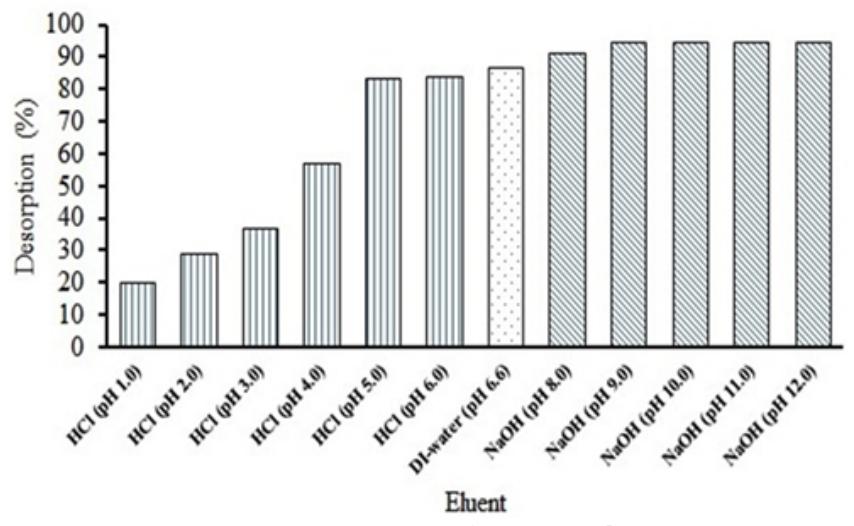

Fig. 11. Desorption of Direct Red-28

\section{Conclusions}

So it is obvious from these results that microwave treated Gardenia jasminoides leaves can be easily prepared within few minutes and they can be effectively employed for adsorption of cationic dyes, like Direct Red-28, using optimum conditions of adsorption parameters. The maximum DR removal capacity of microwave treated sample was $84.50 \mathrm{mg} / \mathrm{g}$ which was 2.5 times greater than that of simple Gardenia jasminoides leaves $=35.13 \mathrm{mg} / \mathrm{g}$. Equilibrium data was well fitted to pseudo second-order kinetic model, indicating overall sorptive removal of DR dye is controlled by bulk mass transfer at initial stages of adsorption, follow ed by internal diffusion to inner layers of MTGL. Thermodynamic investigations indicate the spontaneity and exothermic nature of process. Desorption studies shown that MTGL can easily be regenerated by $\mathrm{NaOH}$ solution. So, it is evident that Gardenia jasminoides leaves can be used to remove Direct Red-28 from waste water, after microwave treatment, in more effective way.

\section{References}

1.ABDELWAHAB, 0., Desalination, 222, 2008, p. 357

2.ABDOLALI, A.W., GUO, S., NGO, H.H., CHEN, S.S., NGUYEN, N.C., TUNG, K.L., Bioresource Technol., 160, 2014, p. 57

3.AFKHAMI, A., MOOSAVI, R., J .Hazard.Mater., 174, 2010, p. 398

4.AHMAD, R., KUMAR, R., Appl.Surf.Sci., 257, 2010, p. 1628

5AHMED, M.J. .K., AHMARUZZAMAN, M., REZA, R.A., J .Colloid Interf.Sci., 428,2014, p. 222

6. AKKAYASAYĐILI, G., J.Mol.Liq., 211, 2015, p. 515

7. AKSU, Z., Process Biochem., 40, 2005, p. 997

8.ASGHER, M., BHATTI, H.N., Ecol.Eng., 38, 2012, p. 79

9.BINUPRIYA, A.R., SATHISHKUMAR, M., SWAMINATHAN, K., KUZ, C.S., YUN, S.E., Bioresource Technol., 99, 2008, p. 1080

10. BULUT, E.,OZACAR, M., SENGIL, Y.A., J.Hazard.Mater., 154, 2008, p. 613

11.CHAKRABORTY, S., BASAK, B., DUTTA, S., BHUNIA, B., DEY, A., Bioresource Technol., 147, 2013, p. 662 
12.CHATTERJEE, S., LEE, D.S., LEE, M.W., WOO, S.H., Bioresource Technol., 100, 2009, p. 3862

13.CHATTERJEE, S., LEE, D.S., LEE, M.W., WOO, S.H., Bioresource Technol., 100, 2009, p. 2803

14. CHATTERJEE, S., LEE, M.W., WOO, S.H., Bioresource Technol., 101,2010, p. 1800

15. DAW OOD, S., SEN, T.K., Water Res., 46, 2012, p. 1933

16. DU, Q., SUN, J., LI, Y., YANG, X., WANG, X., WANG, Z., XIA, L., Chem.Eng.J., 245, 2014, p. 99

17. FU, Y., VIRARAGHAVAN, T., Adv.Environ.Res., 7, 2002, p. 239

18. GHAEDI, M., TAVALLALI, H., SHARIFI, M., KOKHDAN, S.N., ASGHARI,

A., Spectrochim.Acta A, 86, 2012, p. 107

19. HAN, R., DING, D., XU, Y., ZOU, W., WANG, Y., LI, Y., ZOU, L., Bioresource Technol., 99, 2008, p. 2938

20. HOU, H., ZHOU, R., WU, P., WU, L., Chem.Eng.J ., 211, 2012, p. 336

21. LIAN, L., GUO, L., GUO, C., J.Hazard.Mater., 161, 2009, p. 126

22. LIAN, L., GUO, L., WANG, A., Desalination, 249, 2009, p. 797

23. LIU, S., DING, Y., LI, P., DIAO, K., TAN, X., LEI, F., ZHAN, Y., LI, Q., HUANG, B., HUANG, Z., Chem.Eng.J ., 248, 2014, p. 135
24. MANE, V.S., VIJ AY BABU, P.V., J.Taiwan Inst.Chem.E., 44, 2013, p. 81 25.MITTAL, A., MITTAL, J., MALVIYA, A., GUPTA, V.K., J.Colloid Interf.Sci., 340, 2009, p. 16

26. NAMASIVAYAM, C., KAVITHA, D., Dyes Pigments, 54, 2002, p. 47

27. WANG, S.C., TSENG, T.Y., HUANGA, C.M., TSAI, T.H., J .Chromatogr.B, 812, 2004, p. 193

28. BHATTI, H.N., MUMTAZ, B., HANIF, M.A., NADEEM, R., Process Biochem., 42,2007, p. 547

29. PATEL, H., VASHI, R.T., J.Saudi Chem.Soc., 16, 2012, p. 131

30. PATHANIA, D., SHARMA, A., SIDDIQI, Z.M., J.Mol.Liq., 219, 2016, p. 359

31. PURKAIT, M.K., MAITI, A., DASGUPTA, S., DE, S., J.Hazard.Mater., 145, 2007, p. 287

32. RAHIMI, R., KERDARI, H., RABBANI, M., SHAFIEE, M., Desalination, 280, 2011, p. 412

33. SALLEH, M.A.M., MAHMOUD, D.K., KARIM, W.A.W.A., IDRIS, A., Desalination, 280, 2011, p. 1

34. WANG, M.M., WANG, L., Water Sci.Eng., 6, 2013, p. 272

Manuscript received: 15.05 .2018 